\title{
DESIGN OF WIDE BAND AMPLIFIERS USING HYBRID INTEGRATED TECHNIQUES
}

\author{
AUREL SONKOLY \\ Industrial Research Institute for Electronics, "HIKI", 1148 Budapest, Fogarasi üt 14, Hungary
}

(Received October 11, 1977, in final form March 1, 1978)

\begin{abstract}
This article deals with the design of wide band transistor amplifiers. The effects of parasitic elements are significant in the high frequency circuits mounted traditionally and they can only be partially computed. That is why, at present, good quality wide band transistor amplifiers can only be realized using hybrid techniques in an economical production environment. Precise equivalent circuits of high frequency transistors cannot be given, so these devices are characterized by the scattering parameters. Using a digital computer in order to analyse transistor amplifiers the impedance, admittance, transmission and scattering parameters must be converted rationally. To compensate the circuits at high frequencies inductive elements are needed. Using thin film hybrid techniques, the inductor can be realized on a ceramic substrate as an open, i.e. asymmetrical, microstrip transmission line section.

Up to now, in our institute, two circuit families of wide band amplifiers based on the above thin film hybrid principles have been produced. These circuits are designed for use as general purpose amplifiers but they are also suitable for CATV and measuring systems.
\end{abstract}

\section{INTRODUCTION}

In high frequency circuits mounted traditionally, the effects of parasitic elements cannot be avoided. By application of hybrid techniques, good quality wide band transistor amplifiers can be obtained. At present, use of this technology gives the most economical production.

Multilayer chip capacitors are especially suitable for high frequency applications because they have very low lead inductance which gives the required high resonance frequency. Capacitors become inductive above the resonance frequency.

The inductance of the small size thin film resistors is also low compared to that of traditional resistors. If the lead inductance of a resistor is $1 \mathrm{nH}$, the inductive reactance is $6.28 \mathrm{ohm}$ at $1 \mathrm{GHz}$ which is significant for low value resistors. Values of impedance and admittance parameters cannot be measured accurately at frequencies above $100 \mathrm{MHz}$ to $200 \mathrm{MHz}$ because it is difficult to establish the required short and open circuit conditions. Open and short terminations have significant lead inductance and capacitance and they induce measuring uncertainty at high frequencies. Short circuits often cause the active elements to oscillate.

Precise equivalent circuits for high frequency transistors may not be given by the manufacturers. High frequency performance data of transistors are frequently given in the form of scattering parameters $(S)$ by the manufacturers. To define scattering parameters the two-port device must be terminated at both ports by a pure resistance of value $Z_{0}$ called the reference impedance. It can be easily realized and the length of measuring cable does not interfere with the results. ${ }^{1}$

\section{APPLYING NETWORK ANALYSIS TO TWO-PORT PARAMETERS}

The two-port network parameters have to be known

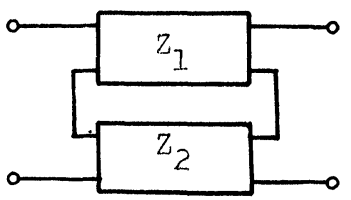

$\mathrm{Z}=\mathrm{Z}_{1}+\mathrm{Z}_{2}$

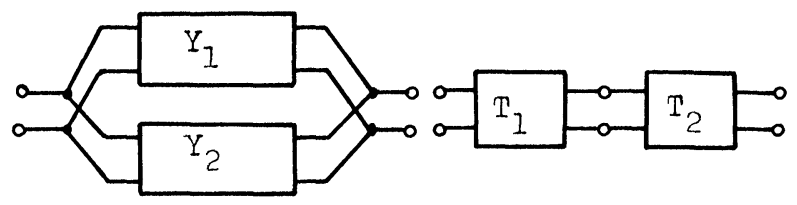

$Y=Y_{1}+Y_{2}$

$\mathrm{T}=\mathrm{T}_{1} \mathrm{XT}_{2}$

FIGURE 1 Connection of two-port networks. 
for circuit design. A complicated network can always be broken down into simple two-port networks. In order to analyse the wide band amplifiers, the impedance $(Z)$, admittance $(Y)$, transmission $(T)$ and scattering $(S)$ parameters must be known. The normal definitions of these parameters are assumed.

To analyse the complicated networks connection rules must be used in order to obtain the resultant parameters by simple matrix operations. ${ }^{2}$ In the case of series, parallel or cascade connection of the twoports the overall parameters can be computed by matrix operation according to Figure 1. All matrix operations use complex elements.

\subsection{Parameter Conversions}

The scattering parameters $(S)$ are important as they are easily measured, their physical meaning is simple and they exist in every network. Only six converting programs are needed for analysis (see Figure 2).

For example in the case of $Z$ to $T$ conversion, first the program system converts $Z$ to $S$ and then converts $S$ to $T$. Conversion equations are given by Anderson $^{1}$ and can also be found in other technical literature.

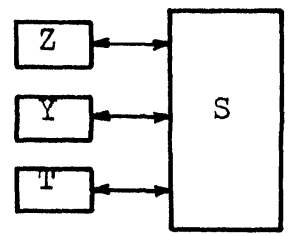

FIGURE 2 Required programs for parameter conversions.

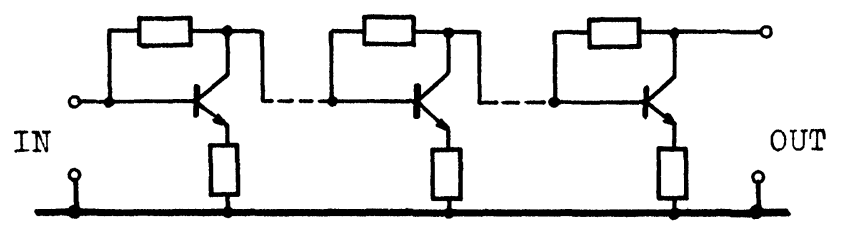

FIGURE 3 Cascaded amplifier.

\subsection{Stability Factor}

The stability is one of the most important characteristics to be dealt with. The feedback networks, the parasitic elements and the scattering parameter $S_{12}$ all cause stability problems.

An amplifier may be conditionally or unconditionally stable. ${ }^{3}$ A circuit is unconditionally stable if there are no values of passive load and source impedances which cause the amplifier to oscillate. A conditionally stable amplifier can be stable but there are values of load and source impedances which cause the amplifier to oscillate.

Stability may be expressed by Rollet's stability factor $K$. Using scattering parameters the stability factor can be computed as:

$$
K=\frac{1+\left|S_{11} S_{22}-S_{12} S_{21}\right|^{2}-\left|S_{22}\right|^{2}-\left|S_{11}\right|^{2}}{2\left|S_{12} S_{21}\right|}
$$

If $K>1$ the amplifier is unconditionally stable. This condition must apply over the desired bandwidth.

\section{COMMON EMITTER TRANSISTOR AMPLIFIERS}

The common emitter configuration is suitable for use in wide band amplifiers because it phase inverts and thus negative feedback may be simply included in the stage. The bandwidth of transistor amplifiers may be considerably increased by negative feedback. The optimum bandwidth and matching can be reached by applying series and parallel feedback to the same stage and these units may be connected in cascade shown in Figure 3.

Additional bandwidth expansion can be obtained by inserting inductive elements. ${ }^{3}$ Several methods are available for choosing the value of the output compensating inductors. (Figure 4, a, b, c).

Considering the output compensation from the point of view of hybrid technology, the arrangement

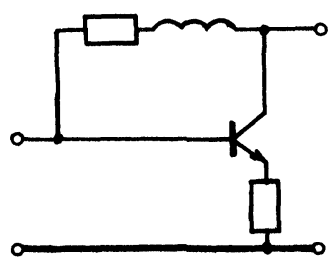

a.

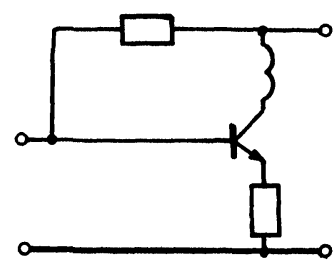

b.

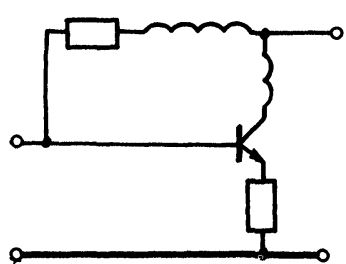

c.

FIGURE 4 Compensation using inductance. 


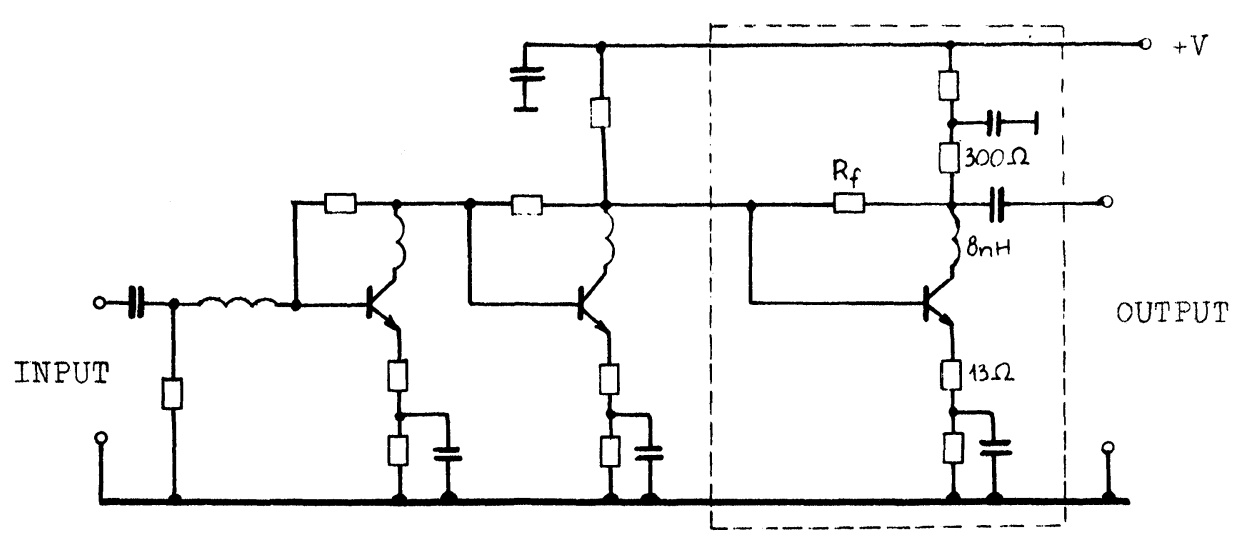

FIGURE 5 Three-stage wide band amplifier.

in Figure $4 \mathrm{~b}$ gives the best solution because the inductor is connected to lower impedances, consequently it may be smaller in value and smaller in area on the substrate.

\section{EXAMPLE FOR CIRCUIT DESIGN}

Consider that a wide band amplifier characterized by the following data is required.

$\begin{array}{ll}\text { Frequency range } & 40 \mathrm{MHz}-860 \mathrm{MHz} \\ \text { Source and load imp. } & 75 \mathrm{ohm} \\ \text { Transducer gain } & G_{t r}>23 \mathrm{~dB} \\ \text { Output voltage } & V_{0}>100 \mathrm{~dB}(\mu \mathrm{V}) \\ \text { Noise figure } & F<6 \mathrm{~dB}\end{array}$

A three-stage transistor amplifier is used (Figure 5) because of wide band width, input and output matching, high gain and low noise.

It is important to choose transistors with optimum characteristics. At the final stage the low intermodulation distortion and high gain required has to be taken into account. In the first stage the most important requirement is low noise across the bandwidth. Transistor type BFR 92 produced by MBLE provides high power gain $(18 \mathrm{~dB})$, very high transition frequency $(5 \mathrm{GHz})$, low intermodulation distortion $(-60 \mathrm{~dB})$ and low noise $(2.4 \mathrm{~dB})$ so this type is suitable for all stages of the amplifier. It has a small reverse transmission coefficient $\left(S_{12}\right)$ giving good stability.

Consider an analysis of the final stage of the amplifier as shown in Figure 5. Computer programs have been written to facilitate design of the amplifier. The circuit graph is built into the program. The following input data must be fed into the program:

- the values of circuit elements

$-S$ parameters of transistors at different frequencies

- frequency points.

TABLE I

The scattering parameters at different frequencies for transistor type BFR 92

\begin{tabular}{|c|c|c|c|c|c|c|c|c|}
\hline \multirow[b]{2}{*}{$\mathrm{f}[\mathrm{GHz}]$} & \multicolumn{2}{|l|}{$S_{11}$} & \multicolumn{2}{|l|}{$S_{12}$} & \multicolumn{2}{|l|}{$S_{21}$} & \multicolumn{2}{|l|}{$S_{22}$} \\
\hline & abs. & $\phi\left[^{\circ}\right]$ & abs. & $\phi\left[^{\circ}\right]$ & abs. & $\phi\left[^{\circ}\right]$ & abs. & $\phi\left[^{\circ}\right]$ \\
\hline 0.1 & 0.343 & -81.6 & 0.017 & 81.7 & 15 & 118 & 0.609 & -38.3 \\
\hline 0.2 & 0.333 & -90 & 0.03 & 80 & 13 & 110 & 0.581 & -40.3 \\
\hline 0.3 & 0.283 & -101 & 0.043 & 78.4 & 10.6 & 101 & 0.548 & -42.4 \\
\hline 0.4 & 0.23 .2 & -115.7 & 0.056 & 76.7 & 8.3 & 93 & 0.513 & -44.7 \\
\hline 0.5 & 0.156 & -128.7 & 0.07 & 75 & 6 & 85 & 0.475 & -47.26 \\
\hline 0.6 & 0.199 & -143.6 & 0.083 & 73.4 & 5.4 & 80 & 0.465 & -48.5 \\
\hline 0.7 & 0.206 & -148.7 & 0.096 & 71.7 & 4.7 & 75 & 0.452 & -49.6 \\
\hline 0.8 & 0.215 & -153.6 & 0.11 & 70 & 4 & 70 & 0.439 & -50.8 \\
\hline 0.9 & 0.208 & -159.8 & 0.115 & 65 & 3.5 & 65 & 0.422 & -49.6 \\
\hline 1 & 0.204 & -166.4 & 0.12 & 60 & 3 & 60 & 0.405 & -52 \\
\hline
\end{tabular}


TABLE II

The scattering parameters and stability factors at different frequencies for the final stage. Obtained by computer

\begin{tabular}{|c|c|c|c|c|c|c|c|c|c|}
\hline \multirow[b]{2}{*}{$\mathrm{f}[\mathrm{GHz}]$} & \multicolumn{2}{|l|}{$S_{11}$} & \multicolumn{2}{|l|}{$S_{12}$} & \multicolumn{2}{|l|}{$S_{21}$} & \multicolumn{3}{|l|}{$S_{22}$} \\
\hline & abs. & $\phi\left[^{\circ}\right]$ & abs. & $\phi\left[^{\circ}\right]$ & abs. & $\phi\left[^{\circ}\right]$ & abs. & $\phi\left[^{\circ}\right]$ & $K$ \\
\hline 0.1 & 0.072 & -40.6 & 0.149 & 1.207 & 2.932 & 162 & 0.066 & 155.56 & 1.349 \\
\hline 0.2 & 0.086 & -40.5 & 0.151 & 3.88 & 2.967 & 157.6 & 0.065 & 144.7 & 1.323 \\
\hline 0.3 & 0.1 & -45 & 0.154 & 6.6 & 3.005 & 151 & 0.062 & 128.9 & 1.296 \\
\hline 0.4 & 0.117 & -56.33 & 0.157 & 9.23 & 3.016 & 142 & 0.057 & 109.9 & 1.277 \\
\hline 0.5 & 0.124 & -70.6 & 0.162 & 12.33 & 2.927 & 127.6 & 0.047 & 78.2 & 1.279 \\
\hline 0.6 & 0.181 & -83.05 & 0.166 & 14.08 & 3.015 & 120.5 & 0.05 & 68.9 & 1.223 \\
\hline 0.7 & 0.23 & -90.9 & 0.172 & 15.8 & 3.047 & 110.9 & 0.049 & 56.3 & 1.174 \\
\hline 0.8 & 0.287 & -101.7 & 0.18 & 17.5 & 2.998 & 98.7 & 0.043 & 39.6 & 1.131 \\
\hline 0.9 & 0.322 & -115.3 & 0.187 & 16.6 & 2.934 & 86.4 & 0.046 & 39 & 1.103 \\
\hline 1 & 0.36 & -131 & 0.2 & 15.6 & 2.77 & 72.1 & 0.024 & 38.9 & 1.086 \\
\hline
\end{tabular}

The output data are the overall $S$ parameters and $K$ stability factors. The program is interactive, thus after changing the value of the elements the new frequency response is given again. For example, the scattering parameters at different frequencies for transistor type BFR 92 are given in Table I. The collector bias current is $15 \mathrm{~mA}$, the collector-emitter voltage is $5 \mathrm{~V}$ and $Z_{0}$ is $75 \mathrm{ohm}$.

The designer needs to know how to vary the value of the correct components in order to influence the overall $S$ parameters. The optimum values of elements must be found. For example the stability may be increased by decreasing the parallel feedback resistor and the gain will be lowered. However low gain is not desirable as it gives a poor noise factor. If for example, $R_{f}=100 \mathrm{ohm}$ (Figure 5) then the program gives $K=1.28, S_{21}=1.411$ and $\phi=129.9^{\circ}$ at 0.7 $\mathrm{GHz}$. The stability is good but the gain is low. If $R_{f}=850 \mathrm{ohm}$, then $K=0.96, S_{21}=3.72$ and $\phi=$ $98.6^{\circ}$ at $0.7 \mathrm{GHz}$. The stability factor $K$ is less than 1 and the circuit is conditionally stable. It can be seen that a high gain circuit is not suitable. It is felt that the best solution can be achieved when the optimum solution is obtained by choosing a gain to give a stability factor only fractionally greater than one over the frequency range. In the example, the optimum value of $R_{f}$ is $350 \mathrm{ohm}$. The scattering parameters and $K$ stability factors of the final stage at different frequencies are shown in Table II.
The circuit is unconditionally stable because $K$ is greater than one over the frequency range. The compensating inductor gives a maximum in the value of $S_{21}$ at $0.7 \mathrm{GHz}$. In order to analyse the whole circuit, the procedure described previously must be repeated for the three stages.

\section{MICROSTRIP TRANSMISSION LINE TECHNIQUE}

Inductors are needed for compensating and matching high frequency wide band amplifiers. Using transmission line section as an inductor, good results can be obtained using hybrid techniques. If the characteristic impedance of a transmission line is higher than the terminating impedance and the length of transmission line is much shorter than the wavelength, then the transmission line replaces an inductor. The transmission line section may be realized as a strip-line. Using asymmetrical (open) microstrip hybrid technique, as in Figure 6, a simple construction can be obtained giving good results.

Approximating equations are available to compute the characteristic impedance of open microstrip transmission lines but use of charts gives a better design result. ${ }^{4}$ The qualitative curve of characteristic impedance of different microstrip lines as a function of $w / h$ is shown in Figure $7 \mathrm{a}(\mathrm{t}<<\mathrm{h}) .(w, h$ and $t$ are defined in Figure 6).

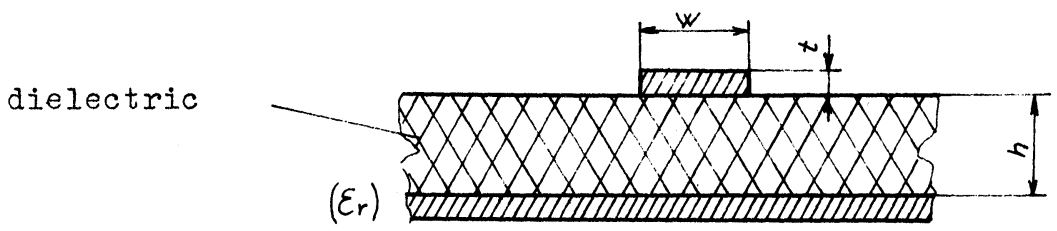

FIGURE 6 Asymmetrical microstrip transmission line. $\epsilon_{r}=$ relative dielectric coefficient. 


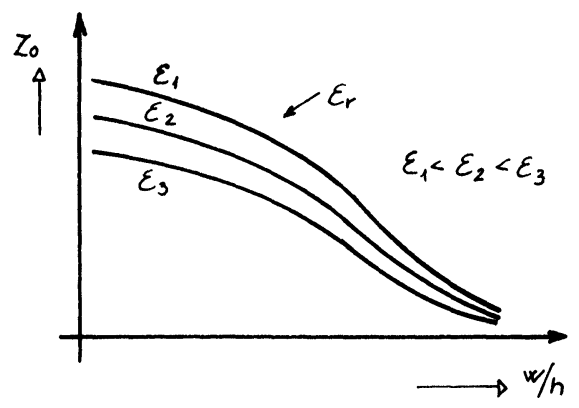

a.

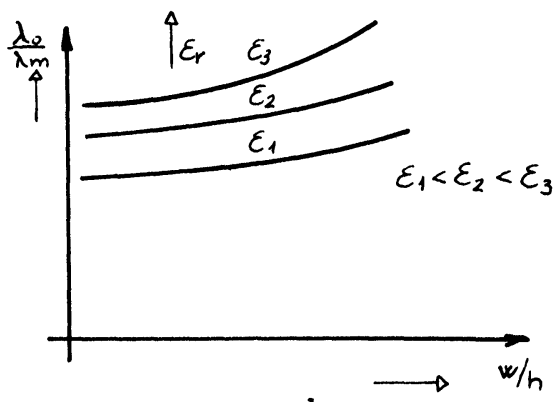

b.

FIGURE 7 Characteristic impedance of a microstrip (a) and the rate of shortening of wavelength in a microstrip (b) as functions of $w / h . \lambda_{0}=$ wavelength in vacuum, $\lambda \mathrm{m}=$ wavelength in microstrip.

The wavelength in the dielectric of a microstrip is shorter than the wave-length in vacuum. The qualitative rate of shortening as a function of $w / h$ is shown in Figure $7 \mathrm{~b}$. The characteristic impedance should be chosen as high as possible and the required length can be computed by applying transmission line theory.

\section{THIN FILM TECHNOLOGY}

In the HIKI institute the substrate used for high frequency thin film circuits is a special ceramic material called SITAL. This material is similar to the normal ceramic substrate but one of the surfaces is glassy to give good adhesive capacity. The thickness of SITAL is $0.6 \mathrm{~mm}$. The relative dielectric constant $\epsilon_{\mathrm{r}}$ is 7 at $1 \mathrm{MHz}$ and is 6.9 at $10 \mathrm{GHz}$. The dielectric loss factor $10^{4} \tan \delta$ is 20 at $1 \mathrm{MHz}$ and is 13 at 10
GHz. The conductors of the thin film circuits are made of $\mathrm{Ni}$ and the resistors are made of NiCr. First, $\mathrm{NiCr}$ film is deposited by evaporation in a vacuum. Then Ni film is deposited by using an electron beam. At a given thickness the ohm/square of Ni film is unity. This value is too high for microstrip transmission line because the series resistance would cause too high a loss. The ohm/square must be decreased by galvanic thickening of the $\mathrm{Ni}$ film with gold. The thickness of $\mathrm{Au}$ film is about $2 \mu \mathrm{m}$, giving an ohm/ square value of about 0.01 which is suitable. $\mathrm{NiCr}$ film with $200 \mathrm{ohm} / \mathrm{square}$ sheet resistance is suitable for the resistor values required.

The circuit is made by the photolithographic process. In order to make an inductor, the width of microstrip transmission line must be small to give a high value of $Z_{0}$. In the high frequency circuits microstrips of width $100 \mu \mathrm{m}$ approx. are used.

TABLE III

Reference data for two kinds of wide band amplifiers

\begin{tabular}{|c|c|c|c|c|}
\hline & & Type I & Type II & Dim. \\
\hline \multicolumn{2}{|l|}{ Frequency range } & $40-860$ & $5-300$ & $\mathrm{MHz}$ \\
\hline \multicolumn{2}{|l|}{ Source and load imp. } & 75 & 75 & $\mathrm{Ohm}$ \\
\hline $\begin{array}{l}\text { Standing wave ratio, } \\
\text { (input and output) }\end{array}$ & $\begin{array}{l}\text { VHF } \\
\text { UHF }\end{array}$ & $\begin{array}{l}<1.5 \\
<2.2\end{array}$ & $<1.5$ & \\
\hline \multicolumn{2}{|l|}{ Transducer gain, $G_{t r}$} & 25 & 16 & $\mathrm{~dB}$ \\
\hline $\begin{array}{l}\text { Flatness of response, } \\
\pm \Delta G_{t r}\end{array}$ & $\begin{array}{l}\text { VHF } \\
\text { UHF }\end{array}$ & $\begin{array}{l}<0.5 \\
<2\end{array}$ & $<0.5$ & $\mathrm{~dB}$ \\
\hline \multicolumn{2}{|c|}{$\begin{array}{l}\text { Output voltage, } V_{0} \\
\text { (at }-60 \mathrm{~dB} \text { intermodulation } \\
\text { distortion) }\end{array}$} & 100 & 108 & $\mathrm{~dB}(\mu \mathrm{V})$ \\
\hline \multicolumn{2}{|l|}{ Noise figure, $F$} & $<5.5$ & $<7$ & $\mathrm{~dB}$ \\
\hline \multicolumn{2}{|l|}{ Supply, $V_{S}$} & +24 & +24 & $\mathrm{~V}$ \\
\hline
\end{tabular}




\section{RESULTS}

Up to now two circuit families of wide band amplifiers based on the given principles of thin film hybrid techniques have been produced. The circuit diagram of the first type can be seen in Figure 5. The circuit diagram of the high level second type is similar to that in Figure 5, but it contains two transistor stages because of lower gain. Reference data for the two kinds of wide band amplifiers are presented in Table III.

These circuits are designed for use as general purpose amplifiers but they are especially suitable for CATV and measuring systems. The low noise can be attributed to the excellent high frequency transistors produced by MBLE and to the well chosen operating point.

\section{CONCLUSIONS}

Good quality reproduceable wide band amplifiers may be realized using hybrid integrated techniques. By applying thin film hybrid technology, the parasitic elements are almost eliminated. More manufacturers are developing special semiconductors for hybrid technology, and considerable progress may be expected in this field.

\section{ACKNOWLEDGEMENT}

The author wishes to thank A. Komar for preparing computer programs and our technologists for their careful work.

\section{REFERENCES}

1. R. W. Anderson, S-Parameters techniques for faster, more accurate network design, Hewlett-Packard Journal (February 1967).

2. Dr. K. Géher, Lineáris hálózatok, Müszaki Könyvkiadó, Budapest (1968).

3. Sturzu Petre, Use CAD to optimize broadband amp. design, Electronic Design, 10, (May 10, 1974).

4. Dr. György Almássy, Mikrohullámu kézikönyv, Müszaki Könyvkiadó, Budapest (1973). 

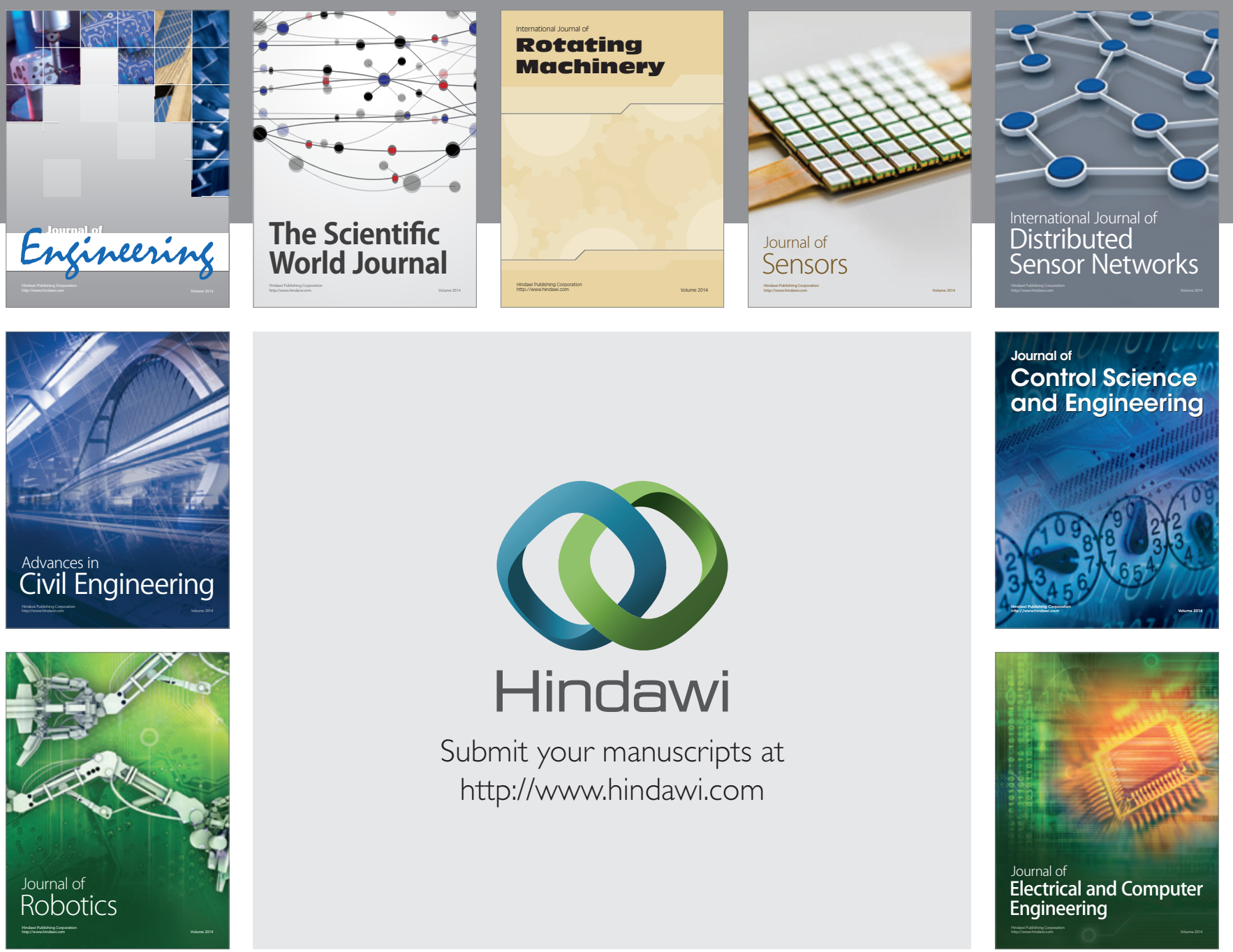

Submit your manuscripts at

http://www.hindawi.com
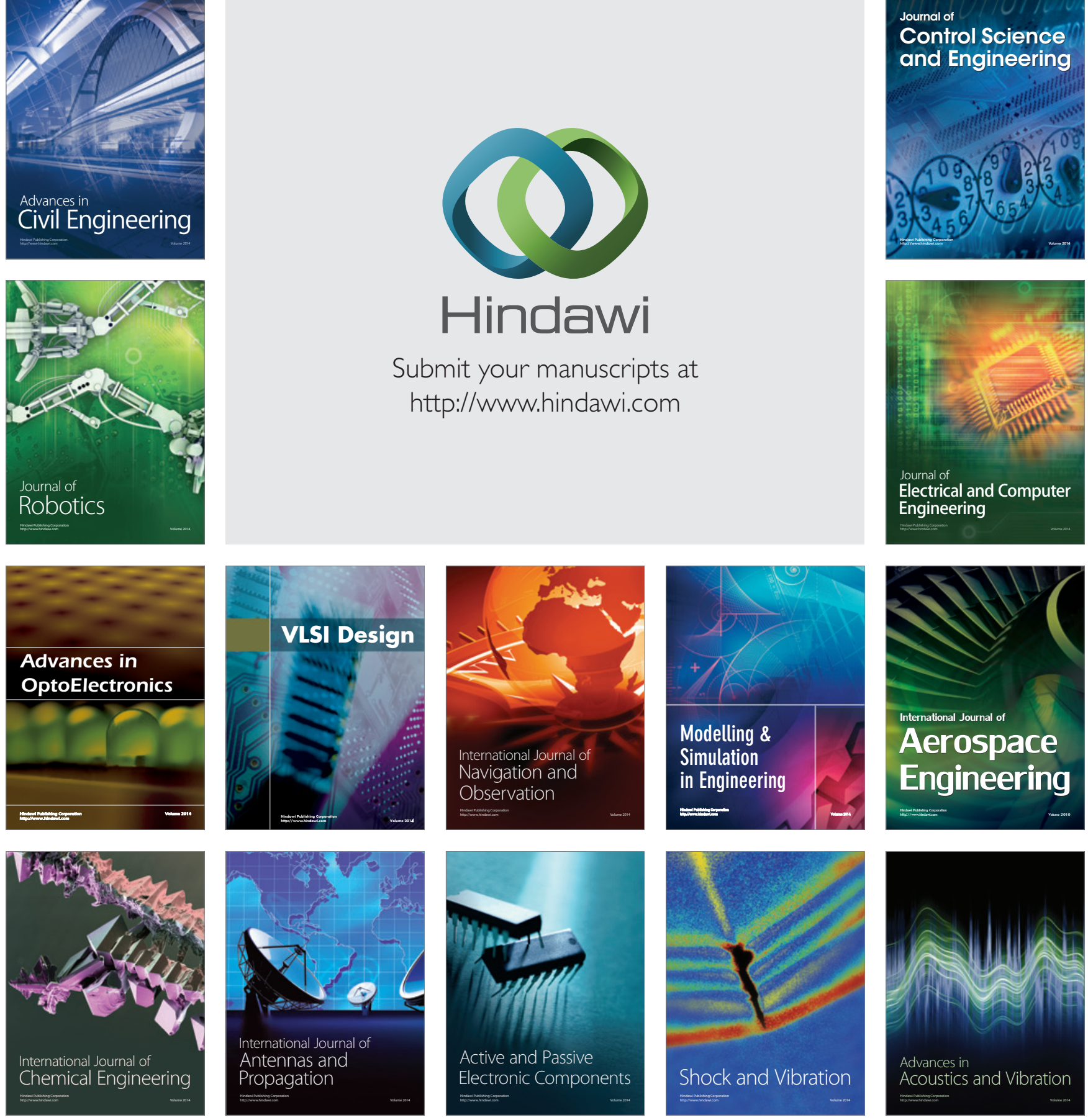